\title{
Making Scholarship Public: Collaboration and Interdisciplinarity in Early Modern Studies
}

\author{
PAUL YACHNIN \\ McGill University
}

\begin{abstract}
How can collaborative, interdisciplinary research on early modern Europe expand the reach of the humanities beyond the academy? In what ways could such a "public turn" enhance the effectiveness of humanities research and teaching? This essay recounts how a number of large, interdisciplinary projects in which the author has been centrally involved grew from scattered intuitions toward collective clarity; how they gathered people from different disciplines around shared questions and changed the ways participants saw their own work; how they enabled students and postdocs to grow as original thinkers by taking part in collaborative research; and how large-scale research that asks big questions might be able to build bridges between the academy and the multiple publics in Canada and beyond in ways that enhance both the university and society.
\end{abstract}

Comment la recherche collaborative et interdisciplinaire en études des débuts de la modernité peuvent atteindre un public au-delà du monde universitaire? Dans quelle mesure cet accès public pourrait améliorer l'efficacité de la recherche et de l'enseignement en sciences humaines? Cet article retrace comment un certain nombre de grands projets interdisciplinaires dans lesquels l'auteur a été impliqué, se sont développés à partir d'intuitions indépendantes vers une vision collective. On y retrace aussi comment ont été rassemblés des chercheurs de différentes disciplines autour de questions communes et comment cela a amené les chercheurs à considérer leur travail différemment, comment ces projets ont permis à des étudiants et des post-doctorants de devenir des chercheurs innovants en participant à des collaborations de recherche, et comment des projets de recherche d'ampleur posant de grandes questions peuvent créer des ponts entre le milieu universitaire et plusieurs publics canadiens et étrangers de façon à faire avancer à la fois l'université et la société.

or the past dozen years it has been my good fortune to have led a number of
collaborative projects in the humanities. One of the projects is still ongoing, with a formal end date of 2018. The work has, I believe, been important for research on early modern Europe, especially for Shakespeare and literary studies, and it has had broader, beneficial effects on humanities research methodologies and on the prospects for an enhanced public life for the humanities. In what follows, I develop an account of the research itself, how it has contributed to new and better historical, aesthetic, ideological, and social understandings of 
early modern works of art and intellect, and how it has helped to reinvent the humanities. An appendix provides basic details about each project. In the essay itself, I focus on the core questions of the research projects themselves and on broader matters-how collaborative, interdisciplinary research works, what obstacles it sometimes throws up in the way of progress, what new avenues of thinking, writing, reading, and teaching it opens up for researchers, and how it can contribute to the advancement of younger scholars.

The work has also changed my life, so this is a story about how one person learned to work across disciplinary boundaries and also across the borders between the academy and the multiple publics outside the university. It is about becoming multilingual (so to speak), learning how complex, large questions can arouse the interest and require the understanding and methods of a wide range of scholars, artists, and members of the public. While it is my story, it also bears, I think, on the experiences and aspirations of many people in different fields, and not just those extraordinarily talented people who took part in the work over the past twelve years.

There are three local, mostly Montreal-centred projects and two international ones. Two of the local ones were the work of the McGill-based Shakespeare and Performance Research Team (SPRiTe), a group of researchers and/or theatre practitioners from McGill, Concordia, Université de Montréal, Université de Québec à Montréal, CEGEP Dawson/Dawson College, the National Theatre School of Canada, and Centaur Theatre. ${ }^{1}$ The first SPRiTe project, Performances of Character: Shakespeare, Theatre, and Critical Practice, ran from 2003 to 2006; the second, Language Incorporated: Culture Markets, Actors' Bodies, and Shakespeare's World of Words, began in 2006 and wrapped up in 2010. A third McGill project, the Shakespeare Moot Court, was a collaborative teaching and research initiative between Desmond Manderson (CRC in Law and Discourse at McGill) and me, which ran from 2002 to 2007 and which drew on and developed the creative and critical intelligence of the sixty-four students, half in Law and half in Graduate Studies in English, who took part in the Moot course over the five years of its life.

From 2005 to 2010, I was director of a SSHRC Major Collaborative Research Initiative project, Making Publics: Media, Markets, and Association in 
Early Modern Europe - the Making Publics (MaPs) Project. ${ }^{2}$ MaPs was an international collaboration of twenty-three faculty researchers and over one hundred students and postdocs as well as eight academic, artistic, and media organizations. In 2013, finally, I was awarded a SSHRC Partnership grant for a second major, international project, Early Modern Conversions: Religions, Cultures, Cognitive Ecologies. ${ }^{3}$ The Conversions Project is a collaboration among thirtyone faculty members from Canada, USA, England, France, Australia, and New Zealand, three postdocs, and-at present-fifty-four graduate student associates. In addition to the lead partner, the Institute for the Public Life of Arts and Ideas at McGill, ${ }^{4}$ there are nineteen academic and artistic partners, including the Centre for Research in the Arts, Social Sciences, and Humanities (CRASSH) at Cambridge, the Newberry Library in Chicago, the Stratford Shakespeare Festival, and the Guildhall School of Music and Drama.

In what follows, I'll discuss each project, mostly by telling each one's story, from initial rough-hewn questions to the emergence of a core idea and a research agenda that were clearer and more coherent than the intuitions with which we started. In each case, the formulation of the central research question was at the heart of the collective work. The process of coming to understand the question itself served in every case to knit together the participating researchers and disciplines into something that could legitimately be called a project.

\section{Performances of Character: Shakespeare, Theatre, and Critical Practice}

In 2002, I left the University of British Columbia to take up a new position at McGill; I joined a strong group of Shakespeare scholars, theatre historians, and theatre practitioners. They had created the Shakespeare Team in 1993 and had fostered an approach to the combined literary and theatrical history and performance practice and study. They had established an excellent track record for funded research, having won two major grants from the Quebec humanities funding agency. The year before I arrived, however, they had hit an obstacle when their application for a third major grant from the Fonds de Recherche sur la Société et la Culture (FQRSC), this one on Global Shakespeare, was not successful.

2. MaPs website, 4 October 2014, http://www.makingpublics.org/.

3. Early Modern Conversions website, 4 October 2014, http://earlymodernconversions.com/.

4. IPLAI website, 4 October 2014, http://www.mcgill.ca/iplai/. 
The best thing to do seemed at first to revise the Global Shakespeare application. After all, the team had already worked on the application, and the ranking had not been completely discouraging. In spite of the apparent strategic advantages of renewing Global Shakespeare, that was not in fact what we did.

Instead we sat face-to-face around a conference table, and all of us talked about our actual research. It emerged that, although we all thought Global Shakespeare was worthwhile, not one of us had a vital investment in questions about early modern dramatic art and the processes of globalization. Clearly, then, this was not the project for us.

What took place in the wake of our realization that none of us was keen to work on Global Shakespeare is to my mind exemplary of collaborative research at its best. This is the first aspect of collaborative research that I want to emphasize. We somehow conjured a topic that was not at all the exclusive property of any one of us but that spoke to each one's interests. It struck each person at the table as important, even necessary. Also, the topic required the particular expertise of every one of us. No one would end up playing second fiddle on the project.

The topic was "Performances of Character." The word "character" had, we felt, enormous resonance in theatrical practice, performance criticism and theory, and literary and historical scholarship. The topic certainly could speak to questions about power and subjectivity and could do so from a specific historical and theoretically informed context. We were attracted by the capacity of the word to serve as a point of exchange between theatrical and critical approaches to Shakespeare. To address the central question "what is character?" it would be necessary to study the history, the formal properties, and the diverse institutional settings of Shakespearean characters. It was an undertaking that could be accomplished only by an interdisciplinary team of researchers-critics, theorists, theatre historians, and theatre practitioners.

We organized the research agenda, especially the first year, so as to develop the cross-over between historical, critical work on the one side and theatrical practice on the other. This is the second important feature: we created a structure that fostered collaboration. For the first year, the team worked together but from various angles on Merchant of Venice. Mike Bristol and $\mathrm{PhD}$ student Sara Coodin focused on Shylock and the Jewish Bible. I studied Shylock and caninity. Myrna Wyatt Selkirk directed a full-scale production of the play, to which we contributed ideas and from which we profited very greatly. 
A third exemplary feature of the Performances of Character project was how the scale and complexity of the question "what is character?" helped induct the students as full-fledged members of the research team. Their work was not secondary; they were not merely labouring in an already defined undertaking but helping to create the project. In turn, their own work was influenced by the gravitational field of the project. Both Gefen Bar-On Santor and Amanda Cockburn, for example, produced early publications that focused on Shakespearean character.

A fourth general feature of the project was how we started to foster substantial exchanges with people outside the university. These exchanges, designed to makes scholarship public, took four principal forms: (1) the production of the play itself, which drew a large diverse audience, (2) a public discussion of the play featuring Kenneth Gross (author of Shylock is Shakespeare) and actor and author Gareth Armstrong, (3) a number of public talks that I presented on the play, and (4) a Merchant of Venice "Playbook," an online guide-book for high schools created by Sara Coodin.

And last, a fifth feature-related to the program of public exchange-was our openness to working with scholars from outside the research team. Sharing the core questions with others has continued to be a key element of the collaborative work over the past twelve years across all the projects I have led. In the case of Performances of Character, the project book, Shakespeare and Character, has chapters by a number of non-team members, including Robert Weimann, Andrew Hartley, and Anthony Dawson.

\section{Language Incorporated: Culture Markets, Actors' Bodies, and Shakespeare's World of Words}

"Shakespeare's World of Words" was in many ways a natural sequel to our project on character. In both cases, we sought to revisit central formal features of Shakespeare's art but not to leave the history or politics out, the overall goal being to fashion a better political criticism by attending to the specificity of dramatic form and theatrical practice.

How, we asked, did Shakespeare grow from a career in the commercial theatre of early modern England into a central, world figure of the literature of modernity? The project aimed to understand Shakespeare's durability and longevity by developing an understanding of (1) the early modern culture market 
and multiplicity of social and literary languages in Shakespeare's works, (2) the ways that Shakespeare wrote for actors so that his language was embodied from the outset, and (3) the relationship between print culture and the emergence of a coherent world of words within Shakespeare's works themselves. The project argued that Shakespeare's cultural longevity and adaptability are strongly related to the linguistic density of his writing, the degree to which he orchestrates the languages of his time and past times as well as the ways of seeing the world that are embedded in those languages.

This project was less exciting in terms of finding our way since we had already developed an interdisciplinary methodology that enabled work between literary-dramatic history and criticism on the one side and theatre-performance history and practice on the other. For example, Patrick Neilson directed a production of Measure for Measure that was in part guided by attention to the word "slip" as well as to the network of words related to "slip" in the play. Then he and I wrote an essay, "Slips of Wilderness: Verbal and Gestural Language in Measure for Measure," that was in turn informed by the rehearsal process and the performance and that argued for seeing Shakespeare's art as theatrical and literary, embodied and verbal, at one and the same time. ${ }^{5}$

While the groundwork had been done already, World of Words was no less challenging or fulfilling than Performances of Character for the work itself, which continued to be highly experimental. One aspect in particular grew significantly: the publication of work by student team members or co-publication between faculty and student members. No chapter in the first project volume is by a student. In the World of Words publication, one is co-authored (Bristol and Coodin) and another is sole authored (Shea). Further, former student members of the Shakespeare Team have published solo or co-published with faculty team members in other venues, including Shakespeare and the Eighteenth Century (2008), Shakespeare and Moral Agency (2010), and Ecocritical Shakespeare (2011).

\section{McGill Shakespeare Moot Court Project}

At a faculty orientation at McGill in 2002, I found myself sitting beside an energetic and outspoken Australian man. We introduced ourselves, he was the new

5. Paul Yachnin and Patrick Neilson, "Slips of Wilderness: Verbal and Gestural Language in Measure for Measure," in Shakespeare's World of Words (London: Bloomsbury / Arden Shakespeare, forthcoming 2015). 
Canada Research Chair in Law and Discourse, and-he told me forcefully-he had a keen interest in Shakespeare and had always wanted to do something on law and Shakespeare.

Desmond Manderson's brilliant idea was to create a moot court where the works of Shakespeare would themselves be the law. We started the course as a sheer experiment with four English grad students and four students in Law. We had to make everything up from scratch-how to rethink Shakespeare as law, how to develop arguments that respected the complexity of Shakespeare's text and that worked in court, how to judge such arguments, what kind of court we were developing, what kind of law we were practising.

As we set it out that first year, the court was an appellant body. In it, students from Law and graduate students from English teamed up to argue cases in the "Court of Shakespeare" (i.e., where the sole Institutes, Codex, and Digest were comprised by the plays of William Shakespeare). The overall aims of the project were to:

(a) provide an organic and responsive model for the ways in which resources to articulate social values can be developed;

(b) explore the ways in which traditions of legal and textual interpretation are created, grown, and modified;

(c) offer new insights into the normative implications of a body of work of supreme cultural significance;

(d) explore the particular nature of Shakespeare's drama, and of literature generally, as an expressive register of normative social values;

(e) consider how literature and literary thinking might influence and might have already influenced law and legal thinking.

Pairing law students with graduate students in literature, the project fostered a formative connection between the discourses of law and the humanities. Law and English students learned about the processes of reasoning and analysis in the other discipline, and they came to appreciate the cultural, institutional, and historical imbrications of their own disciplinary practices.

Over the five years of the Court's existence, Desmond and I invented five fact patterns, each one addressed to a serious, pressing question for modern society. One of these, on same-sex marriage, moved out of the court room into a formal debate between the two of us that attracted over four hundred people 
and was featured on CBC Radio. By the agency of the Court, Shakespeare became in this instance an important conversation partner for people in the twenty-first century.

The students who participated in the Shakespeare Moot Project found themselves at a rare moment of unfettered creativity. They not only studied the emergence and nature of a legal system, they also made one. This was especially the case because the participants created the precedents from which the future legal system has continued to grow. Versions of the Shakespeare Moot Court have run recently at the University of Alberta and the University of Oklahoma.

\section{Making Publics: Media, Markets, and Association in Early Modern Europe}

The Making Publics Project-MaPs-theorized publics and developed an historical account of what publics were in early modern Europe. How did publics-new forms of association built on the shared interests of individuals and on new kinds of artistic and intellectual production-transform European society from 1500 to 1700 ? The project concluded that the study of public making provides a new way of understanding the political dimensions of artistic and intellectual works and opens the way toward a new history of early modernity.

In consultation with secondary school teachers, we created online high school lesson plans and introduced them to teachers and students in Canada and the UK. Two MaPs festivals brought our ideas to large audiences in Toronto and Montreal. CBC Radio IDEAS broadcast a fourteen-episode series, The Origins of the Modern Public, based on MaPs and created by CBC producer David Cayley. ${ }^{6}$ The influence of MaPs has been broad and various. In his book, Public Parts, American business writer Jeff Jarvis credits the project with shaping his thinking about business and public life. ${ }^{7}$

MaPs welcomed younger scholars to the project and helped advance their work. We sponsored over ninety one-term research assistantships. Approximately forty-five graduate students became graduate student associates and took an active part in the project. We recruited nine postdoctoral fellows.

6. The Origins of the Modern Public, 22 November 2014, http://www.cbc.ca/ideas/episodes/features/ 2010/04/26/the-origins-of-the-modern-public/.

7. Jeff Jarvis, Public Parts: How Sharing in the Digital Age Improves the Way We Work and Live (New York: Simon \& Schuster, 2011). 
All of them continue their productive careers in higher education, and five of them have secured tenure-track positions in Canada, the USA, and Australia. MaPs sponsored four summer research seminars. These seminars welcomed forty-eight junior career scholars from all over the world: these young researchers contributed to MaPs and were in turn influenced by MaPs' ideas and methodology. The work of PDFs, GSAs, and summer seminarians appears in the three most recent MaPs publications-the Early Modern Culture special issue, Forms of Association, and the special issue of History Compass.

MaPs was a very successful undertaking, but it was a challenging, even an arduous collaboration for the first years of work. The members of the research team had to put their heads and disciplines together first of all in order to define the object of study, and then they had to change how they thought. Only then was it possible to grasp and explain the social processes of early modern public making.

It began in a flush of excitement. What happened was this: the nascent research team gathered in Montreal in August 2003, two years before what would be the formal start of the project. On the very first morning of the meeting, they balked at my groundwork proposal that early modernity had seen the emergence of a public sphere. Such a rejection of the foundational hypothesis could well have proved fatal for the project.

I was very much relieved when the team decided to stick to the task of imagining a project on the social creativity of works of art and intellect. Toward the end of the first day, they conjured the phrase "making publics." I think it was the late Richard Helgerson who suggested adopting the plural form of "public." David Sacks came up with "making" on the model of E. P. Thompson's The Making of the English Working Class, especially in light of Thompson's emphasis on "poesis" and his idea that the working class was present at its own making (that is, that the working class had participated as a collective agent in its own founding). The plural form alleviated the problem that had confronted the group at the start of the day. With "making publics" as the guiding term, the team did not have to assume the emergence of a public sphere. The problem confronting the project in the morning seemed by the end of the day to have been solved.

What we discovered over the following several years was that the possession of a resonant key phrase was not the same as having a fully formed theory or a workable methodology. It took three years at least to come to terms with 
the meaning of the phrase "making publics" and to begin to develop a coherent account of early modernity as an age characterized by the massive expansion of publics and public-making practices. We learned that publics develop in untrammelled ways because they are separate from the grand world of Church and State. They are significant because of their capacity to induct merely "private" people into a multiplicity of forms of public space and speech and on account of their ability to influence the broader public sphere and the centres of power and authority.

We learned that a big question such as the one we asked about the social creativity of works of art and intellect cannot be answered by any one scholar or any one discipline. We learned that interdisciplinarity is hard. We had to some degree to learn each other's archives and methods. We learned, finally, that the younger scholars who joined the project, the GSAs, the summer seminarians, and the postdoctoral fellows, had a much easier time rewiring their ways of thinking and seeing than had the faculty researchers who began the project. In a project as large and ambitious as MaPs, it is certainly true that the most significant work is done not only among different disciplines but also between older and younger generations.

\section{Early Modern Conversions: Cultures, Religions, Cognitive Ecologies}

The Conversions Project is developing a historical understanding of conversion that will enlighten modern debates about corporeal, sexual, psychological, political, and spiritual kinds of transformation. The project studies how early modern Europeans changed their confessional, social, political, and even sexual identities. These subjective changes were of a piece with transformations in their world - the geopolitical reorientation of Europe in light of emerging relations with Islam and the Americas; the translation of the knowledge of Greek and Latin Antiquity, Christianity, Judaism, and Islam; changes in and changing uses of the built environment; the reimagining of God.

In recent studies of early modern Europe, "conversion" is a term that normally refers to religious phenomena. In contrast, the conversions that we are studying are geopolitical, socio-cultural, material, literary and artistic, racial, human-animal, sexual, as well as religious.

The historical project is building on team members John Sutton and Evelyn Tribble's work on extended mind, distributed cognition, and cognitive 
ecologies, which are, according to one of their essays, "the multidimensional contexts in which we remember, feel, think, sense, communicate, imagine, and act, often collaboratively, on the fly, and in rich ongoing interaction with our environments." Ideas about extended mind and cognitive ecology represent an advance on the model of "the episteme," which tends toward abstraction and generalization. To consider forms of conversion in the terms developed by Sutton and Tribble (among others) is to allow for a plurality of early modern cognitive and affective worlds and to stay closely in touch with the particularities of text, image, and music and with social, artistic, and religious practice.

Also formative is the development of a CFI-funded History Visualization Lab (HVL). Developed under the leadership of co-applicant Stéfan Sinclair, the HVL will make possible a digital analysis of conversion across hundreds of thousands of texts and will display networks of kinds of conversion in visual form on a large interactive map. The visualization technology will enable researchers to see, on a very large scale, how particular forms of conversion emerge at particular times and places, how they move, grow, and subside, and how they interact with other forms.

In addition to a great deal of individual project-related research, the first year has featured five interdisciplinary teams, each addressing the general concerns of the project from a particular angle. These include the Soul, the Sense of Hearing, Early Modern Cities as Theatres of Conversion, Mapping Horizons, and Spaces of Conversion and the Conversion of Space. The next big step is to draw this work together into a historically informed theory of early modern conversion. The task will likely be as challenging as the development of the theory of publics was for the MaPs Project. The work will be supported and encouraged by the development of three volumes of essays. Each volume will include single- and co-authored work, a significant portion of which will be by postdoctoral and student team members.

A significant feature of the Conversions project is the participation of artists alongside scholars in the development of a historical, aesthetic, and theoretical account of conversion. Also important is the commitment to the idea that artistic practice is itself a form of historical research as well as a way of bridging between university research and broader discussions of matters of 
public consequence. We have already begun the work of public engagement and exchange by way of collaborations with the Montreal Baroque Festival, the Stratford Festival, and the Guildhall School of Music and Drama.

In sum, large-scale collaborative, interdisciplinary research projects are challenging, even sometimes overwhelming, but they are also of great value for their capacity to address big questions that could not adequately be handled by a single discipline. Because no single researcher is capable of answering the complex questions that arise in projects such as MaPs or Early Modern Conversions, it is also true that students discover a far greater degree of freedom, responsibility, and creativity than is usually the case for GRAs. The faculty researchers themselves must work hard and with open minds in order to learn something about the other disciplines in the project and in order to begin to think differently. Finally, large collaborative projects are better positioned to ask questions that are able to involve members of the public in the work of the academy. The exchanges borne of this involvement are of great benefit to the public, who stand to learn something important about the history of their own habits of mind-their ideas about private and public life, their fascination with personal transformation. It is also of great value to the university itself, since the university, if it is to survive and flourish, must transform its idea of itself from a fortress of knowledge and credentialization to a centre for public exchange of learning and teaching and a home for deep, critical analysis in dialogue with the multiple publics of Canadian society. But that, as they say, is a question for another day. 


\section{Appendix}

(1) Performances of Character: Shakespeare, Theatre, and Critical Practice, 2003-2006

Shakespeare and Performance Research Team

Funding: Fonds de Recherche sur la Société et la Culture (FQRSC)

For details about members of the Shakespeare Team, see http://mcgillshakespeare.com/

\section{Selected Publications}

Gefen Bar-On Santor, "Looking for 'Newtonian' Laws in Shakespeare: The Mystifying Case of Hamlet," in Shakespeare and the Eighteenth Century, ed. Peter Sabor and Paul Yachnin (Aldershot: Ashgate, 2008), 151-64.

Amanda Cockburn, "Awful Pomp and Endless Diversity: The Sublime Sir John Falstaff," in Shakespeare and the Eighteenth Century, 137-50.

Paul Yachnin and Jessica Slights, ed., Shakespeare and Character: Theory, History, Performance, and Theatrical Persons (London: Palgrave, 2009).

(2) Language Incorporated: Culture Markets, Actors' Bodies, and Shakespeare's World of Words, 2006-2010

Shakespeare and Performance Research Team

Funding: FQRSC

\section{Selected Publications}

Michael Bristol and Sara Coodin, "Well-Won Thrift," in Shakespeare's World of Words, ed. Paul Yachnin (London: Bloomsbury / Arden Shakespeare, 2015).

J. A. Shea, "Recasting 'Angling' in The Winter's Tale," in Shakespeare's World of Words (London: Bloomsbury / Arden Shakespeare, forthcoming 2015).

Keira Travis, "Wordplay and the Ethics of Self-Deception in Shakespeare's Tragedies," in Shakespeare and Moral Agency, ed. Michael D. Bristol (London: Continuum, 2010), 42-54.

Paul Yachnin, ed., Shakespeare's World of Words (London: Bloomsbury / Arden Shakespeare, forthcoming 2015). 
(3) McGill Shakespeare Moot Court Project, 2002-2007

Desmond Manderson (Law) and Paul Yachnin, co-directors

Funding support: Canada Research Chair Program

\section{Selected Publications}

Desmond Manderson, Paul Yachnin, et al., "Love on Trial: Nature, Law, and Same-Sex Love in the Court of Shakespeare," McGill Law Journal 49 (2004): 475-511.

Manderson, Yachnin, Peter Goodrich et al., "Not Drowning, Waiving: Responsibility to Others in the Court of Shakespeare," Law, Culture and the Humanities 4 (2008): 20-69.

Desmond Manderson, "Judgment in Law and the Humanities," in Law and the Humanities: An Introduction (New York: Cambridge University Press, 2009), 496-516.

Manderson and Yachnin, "Shakespeare and Judgment: The Renewal of Law and Literature," The European Legacy 15 (2010): 195-213.

Paul Yachnin, "Rejoicing in the Law: The Performance of Authorship in A View from the Bridge," Zeitschrift für Anglistik und Amerikanistik 60.1 (2012): 77-89.

(4) Making Publics: Media, Markets, and Association in Early Modern Europe, 2005-2010

SSHRC Major Collaborative Research Initiative

For faculty project members, see http://project.makingpublics.org/ members/

Younger scholars (selected)

Jen Drouin (PhD, English, McGill, 2005; Humanities Computing PDF, 200508), TT, University of Alabama

Marlene Eberhart (DM, Indiana University, 2004; PDF / Project Manager, 2005-10) teaches music history at Vanier College and Humanities at Dawson College

Miriam Jacobson (PhD, English, Penn State, 2005; PDF 2005-06) TT, University of Georgia

Leigh Yetter (PhD, History, Brown; PDF 2006-08), Senior Director, Office of the Provost, McGill 
Matthew Milner (PhD, History, Warwick; PDF Humanities Computing, 200811) Digital Humanities Coordinator for the Faculty of Arts, McGill

Vera Keller (PhD, History, Princeton 2008; PDF 2008-10) TT, Honors College, University of Oregon

Javier Castro Ibaseta ( $\mathrm{PhD}$, History, Universidad Autonoma de Madrid; Summer Seminarian 2008) Assistant Professor, University of Michigan

Rosa Salzberg (PhD, History, University of London; Summer Seminarian 2009) TT, Warwick University

\section{Selected Publications}

Jeffrey Doty, 'Shakespeare's Richard II, 'Popularity', and the Early Modern Public Sphere," Shakespeare Quarterly 61 (2010): 183-205.

Patricia Fumerton, ed., "Printing Publics: A Special Issue Dedicated to the Memory of Richard Helgerson," Early Modern Culture (2010) http://emc. eserver.org/.

Robert Tittler, Portraits, Painters, and Publics in Provincial England, 1540-1640 (Oxford: Oxford University Press, 2012).

Angela Vanhaelen and Joseph Ward, ed., Making Space Public in Early Modern Europe: Performance, Geography, Privacy (London: Routledge, 2014).

Bronwen Wilson and Paul Yachnin, ed. Making Publics in Early Modern Europe: People, Things, Forms of Knowledge (London: Routledge, 2010).

Paul Yachnin and Marlene Eberhart, ed., Forms of Association: Making Publics in Early Modern Europe (Amherst: University of Massachusetts Press, forthcoming).

(5) Early Modern Conversions: Cultures, Religions, Cognitive Ecologies, 2013-2018

SSHRC Partnership Program

History Visualization Lab

CFI-Leaders Opportunity Fund, Director: Stéfan Sinclair

For details, see http://earlymodernconversions.com/ 
